\title{
Changes of proteins induced by anticoagulants can be more sensitively detected in urine than in plasma
}

\author{
LI MengLin, ZHAO MinDi \& GAO YouHe \\ National Key Laboratory of Medical Molecular Biology, Department of Physiology and Pathophysiology, Institute of Basic Medical Sciences, \\ Chinese Academy of Medical Sciences, School of Basic Medicine, Peking Union Medical College, Beijing 100005, China
}

Received December 29, 2013; accepted March 14, 2014; published online June 6, 2014

\begin{abstract}
The most fundamental property of biomarkers is change. But changes are hard to maintain in plasma since it is strictly controlled by homeostatic mechanisms of the body. There is no homeostatic mechanism for urine. Besides, urine is partly a filtration of blood, and systematic information can be reflected in urine. We hypothesize that change of blood can be reflected in urine more sensitively. Here we introduce the interference into the blood by two anticoagulants heparin or argatroban. Plasma and urine proteins were profiled by LC-MS/MS and then validated by Western blot in totally six SD female rats before and after the drug treatments. In argatroban treated group, with exactly the same experimental procedure and the same cutoff value for both plasma and urine proteins, 62 proteins changed in urine, only one of which changed in plasma. In heparin treated group, 27 proteins changed in urine but only three other proteins changed in plasma. Both LC-MS/MS and Western blot analyses demonstrated drug-induced increases in transferrin and hemopexin levels in urine but not in plasma. Our data indicates that urine may serve as a source for more sensitive detection of protein biomarkers than plasma.
\end{abstract}

biomarker, homeostasis, urine, plasma, proteomics

Citation: $\quad$ Li ML, Zhao MD, Gao YH. Changes of proteins induced by anticoagulants can be more sensitively detected in urine than in plasma. Sci China Life Sci, 2014, 57: 649-656, doi: 10.1007/s11427-014-4661-y

In comparison to plasma, urine has advantages as a source for biomarker discovery. First, urine can be collected non-invasively, frequently and in large quantities. Second, while plasma is generally obtained at a single time point, multiple urine samples can be collected over a period of time, allowing for an easier monitoring of time-dependent changes in biomarker levels. Third, proteolytic degradation may be complete prior to collection of urine [1,2] and because proteases are activated during blood collection [3], the urinary proteome shows much greater stability compared with that of plasma. Urinary proteins, for example, show no significant changes when urine is stored for $3 \mathrm{~d}$ at $4^{\circ} \mathrm{C}$ or for $6 \mathrm{~h}$ at room temperature [4,5]. The use of membranes to store urinary proteins is simple and economical

*Corresponding author (email: gaoyouhe@pumc.edu.cn) and facilitates biomarker research by making large-scale storage of clinical urinary samples possible [6].

Most importantly, theoretical considerations suggest that urine may be a better source for biomarker discovery than plasma. Given that change is an essential property of a biomarker, the strict homeostatic regulation of plasma composition would in theory act to correct any changes in biomarker levels. While urine collects all waste from the body, it can accumulate more and bigger changes [7]. Therefore, urine serves not only as an ideal source of biomarker discovery for diseases of the kidney and other tissues of the urogenital system but also as a potential source of information on diseases in other physiological systems.

We used two different anticoagulants (unfractionated heparin and argatrabon) to disrupt the blood coagulation status of adult female SD rats. Rat model was selected be- 
cause the urine from rats could be more easily collected than that from mice, since the volume and amount of urinary proteins were higher than those of mice. We then compared the sensitivity of detection of changes in urine and plasma proteomic profiles in response to treatment with the drugs, to observe whether changes in urine can be more sensitively detected.

\section{Materials and methods}

\subsection{Ethics statement}

Adult female Sprague-Dawley rats were purchased from the Institute of Laboratory Animal Science, Chinese Academy of Medical Science. The experiment was approved by Institutional Animal Care Use \& Welfare Committee of Institute of Basic Medical Sciences, Peking Union Medical College (Animal Welfare Assurance Number: ACUC-A02-2013015). All animals were kept with standard laboratory diet under controlled indoor temperature $\left(22 \pm 1^{\circ} \mathrm{C}\right)$ and humidity $(65 \%-70 \%)$. The study was performed consistently with guidelines developed by Institutional Animal Care Use \& Welfare Committee of Institute of Basic Medical Sciences.

\subsection{Anticoagulants treatment of rats}

Six adult female Sprague Dawley rats were initially anaesthetized by an intravenous injection of $20 \mathrm{mg} \mathrm{kg}^{-1}$ pentobarbital sodium, after which a catheter was inserted for urine sampling. Saline $(0.9 \% \mathrm{NaCl}$ in sterile water) was first administered via the great saphenous vein as a single bolus with a volume equivalent to that of the anticoagulants. Urine was collected over the following $30 \mathrm{~min}$ as a control specimen. Rats then received a bolus of argatroban $\left(2 \mathrm{mg} \mathrm{kg}^{-1}\right)$ via the same vein, after which urine was collected over the following $30 \mathrm{~min}$. Only rats that showed no gross hematuria were considered to be successful preparations and the next stage proceeded. Urine was centrifuged at $3000 \times g$ for $10 \mathrm{~min}$ at $4^{\circ} \mathrm{C}$. After removal of precipitates, urinary proteins were extracted by acetone precipitation [8] and subjected to quantitation by the Bradford method.

Venous blood was collected by aspiration from the femoral vein at three time points: $5 \mathrm{~min}$ after saline injection and 5 and $30 \mathrm{~min}$ after administration of anticoagulants. For the assessment of clotting time (CT), $25 \mu \mathrm{L}$ of the blood sample was used. The remaining blood sample was immediately transferred to a plastic tube containing $0.109 \mathrm{~mol} \mathrm{~L}^{-1}$ sodium citrate at a ratio of $1: 9$, gently mixed and centrifuged at $2000 \times g$ at $4^{\circ} \mathrm{C}$ for $10 \mathrm{~min}$ to obtain citrated plasma. Plasma was stored at $-80^{\circ} \mathrm{C}$ until further analysis.

Heparin $\left(5 \mathrm{mg} \mathrm{kg}^{-1}\right)$ was given intravenously to another group of rats by the same procedure as argatrabon experiment described above.

\subsection{Determination of clotting time and activated par- tial thromboplastin time}

CT was measured as previously reported [9]. Activated partial thromboplastin time (APTT) determination was performed using the External diagnostic reagent kit (Shanghai Taiyang Shengwu Technique Co., China) according to the manufacturer's instructions.

\subsection{Protein digestion and peptide preparation}

Urine and plasma proteins were digested with trypsin (Trypsin Gold, Mass Spec Grade, Promega, USA) by FASP [10] using $10 \mathrm{kD}$ Pall filtration devices (Pall Corporation, USA). Peptides were desalted using a $1 \mathrm{~mL}$ OASIS HLB cartridge (Waters, Milford, MA, USA) according to the manufacturer's instructions. The eluate was dried via vacuum evaporation and stored at $-20^{\circ} \mathrm{C}$ until LC-MS/MS analysis.

\subsection{LC-MS/MS analysis}

Lyophilized peptides were re-dissolved in $0.1 \%$ formic acid and subjected to chromatography using a Waters UPLC system. Peptides were separated on a $10-\mathrm{cm}$ fused silica column packed in-house using ReproSil-Pur C18-AQ (3 $\mu \mathrm{m}$ resin). Elution was performed over a gradient of 5\%-28\% buffer B $(0.1 \%$ formic acid, $99.9 \% \mathrm{ACN}$; flow rate, $0.3 \mu \mathrm{L}$ $\min ^{-1}$ ) for $100 \mathrm{~min}$. MS data were acquired using a Triple TOF MS system. Three technical replicate analyses were performed for each sample.

\subsection{Database searching and protein identification}

MASCOT server (version 2.4; Matrix Science, UK) was used for database searching against the Swissprot_Rat database (data 05/03/2013, 9354 sequences). Search parameters were set as follows: tryptic cleavages at only lysine or arginine with up to two missed cleavage sites allowed, fixed cysteine carbamidomethylation, variable glutamine deamidation and variable methionine oxidation. The precursor mass tolerance was set to $0.05 \mathrm{Da}$ and the fragment mass tolerance to $0.05 \mathrm{Da}$.

Scaffold (version Scaffold_4.0.4, Proteome Software Inc., Portland, OR, USA) was used to validate MS/MS based peptide and protein identifications. Peptide identifications were accepted if they could be established at greater than $90.0 \%$ probability to achieve an FDR less than $0.1 \%$ by the Scaffold Local FDR algorithm [11]. Protein identifications were accepted if they could be established at greater than 95.0\% probability and contained at least two identified peptides. Proteins that contained similar peptides and could not be differentiated based on MS/MS analysis alone were grouped to satisfy the principles of parsimony. 


\subsection{Label-free quantitation and statistical analysis}

The acquired spectra were loaded into the Progenesis software application (version 2.5, Nonlinear UK (Progenesis LC-MS)) for label free quantification. The spectra were analysed according to the procedure described by Hauck et al. [12]. Following criteria were applied to increase the credibility of protein identification and quantification. First, proteins identified by a single peptide were excluded. Second, we required that the direction of change in each animal be consistent and the fold change be $\geqslant 1.5$ in at least one animal.

\subsection{Western blot analysis}

Urine and plasma proteins $(20 \mu \mathrm{g} / \mathrm{lane})$ were separated using $10 \%$ SDS-PAGE and blotted onto Immobilon PVDF transfer membranes (Millipore, USA) using the wet transfer system (Bio-Rad, USA), with $25 \mathrm{mmol} \mathrm{L}^{-1}$ Tris-HCl, 192 mmol L ${ }^{-1}$ glycine, $\mathrm{pH} 8.3$, and $15 \%$ methanol as the transfer buffer. All antibodies were purchased from Abcam (UK). For Western blot analyses, primary antibodies were used at 1:1000 dilution and secondary antibodies (anti-rabbit HRP) at 1:10000 dilution. Blots were developed using ECL (Engreen Biosystem Co., Ltd., China). ECL results were scanned and analyzed using an ImageQuant $400^{\mathrm{TM}}$ Imager (GE Healthcare Life Sciences, USA) and the intensity of each protein band was quantified using Image $\mathbf{J}$ analysis software (National Institutes of Health, USA).

\section{Results}

\subsection{Anticoagulants increased CT and APTT in rats}

CT and APTT were increased in both heparin- and argatroban-treated rats (Figure 1). APTT is the period required for clot formation in recalcified blood after contact activation and the addition of platelet substitutes. It is used to evaluate the intrinsic and screen for bleeding tendencies. $\mathrm{CT}$ is the period required for blood to clot in a glass tube. The prolonged CT and APTT indicate that the coagulation status is disrupted by the anticoagulants.

\subsection{Detection of changes in the protein composition of urine and plasma using label-free quantification}

On 1 D SDS-PAGE gel, urinary protein pattern did not show singnificant and consistent change before and after anticoagulants administration (Figure $\mathrm{S} 1$ in Supporting Information).

The identical proteomic analysis approach was used to analyze the protein composition of rat urine and plasma samples before and after treatment with anticoagulants. Software Progenesis was used to perform label-free quantification. The details of criteria are described in Materials and methods. Briefly, for protein identification, the false
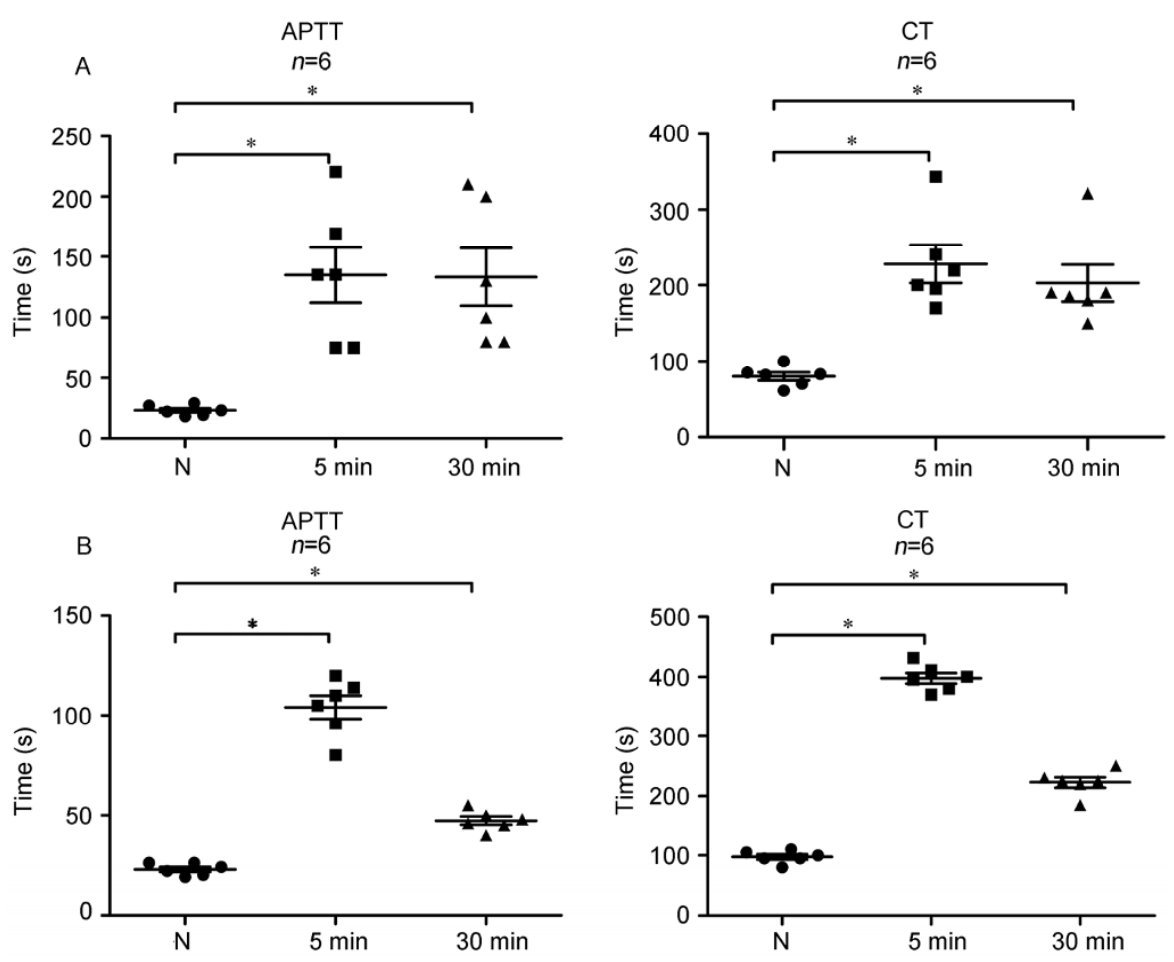

Figure 1 Effects of intravenous bolus injections of argatroban and heparin on CT and APTT. A, APTT and CT increased in heparin treated group ( $n=6)$. *, $P<0.005$. The anticoagulants were administered 30 min after the injection of the isometric saline. The CT and APTT were assayed 5 min after saline injection $(\mathrm{N})$ and 5 and $30 \mathrm{~min}$ after anticoagulant injection ( 5 and $30 \mathrm{~min})$. B, APTT and CT increased in argatroban treated group ( $n=6)$. * $P<0.001$. 
positive rate was $1 \%$. For quantification, only unique peptides and proteins with at least two peptides were included. Besides, the direction of change in each animal should be consistent and the fold change should be $\geqslant 1.5$ in at least one animal.

LC-MS/MS analysis detected consistent heparin-induced changes in the levels of 27 proteins in urine but only three proteins in plasma (Table 1). There was no overlap between these groups of proteins. Consistent changes in the levels of 62 proteins were detected in urine in response to treatment with argatroban, only one of which changed in plasma (Table S1 in Supporting Information). The number of proteins identified in plasma was much smaller than the number detected in urine (Table S2 in Supporting Information). These results indicate that changes in protein levels may be more sensitively detected using LC-MS/MS in urine than in plasma.

\subsection{Validation of changes in protein levels by Western blot}

Additional six animals were treated with anticoagulants to validate LC-MS/MS analysis of changes in the plasma and urine by Western blot. Plasma and urine samples were collected following the procedure described in Materials and methods, and transferrin and hemopexin were selected for validation. In accordance with changes in the levels of these proteins observed via the LC-MS/MS analysis, changes in the levels of both proteins in response to anticoagulant treatment were observed in urine but not in plasma (Figure 2).

\subsection{Functional analysis of the differential proteins}

Functional analysis of these differential proteins was performed by the Ingenuity Pathway Analysis (IPA) tool

Table 1 Changed proteins in heparin treated group ${ }^{\text {a) }}$

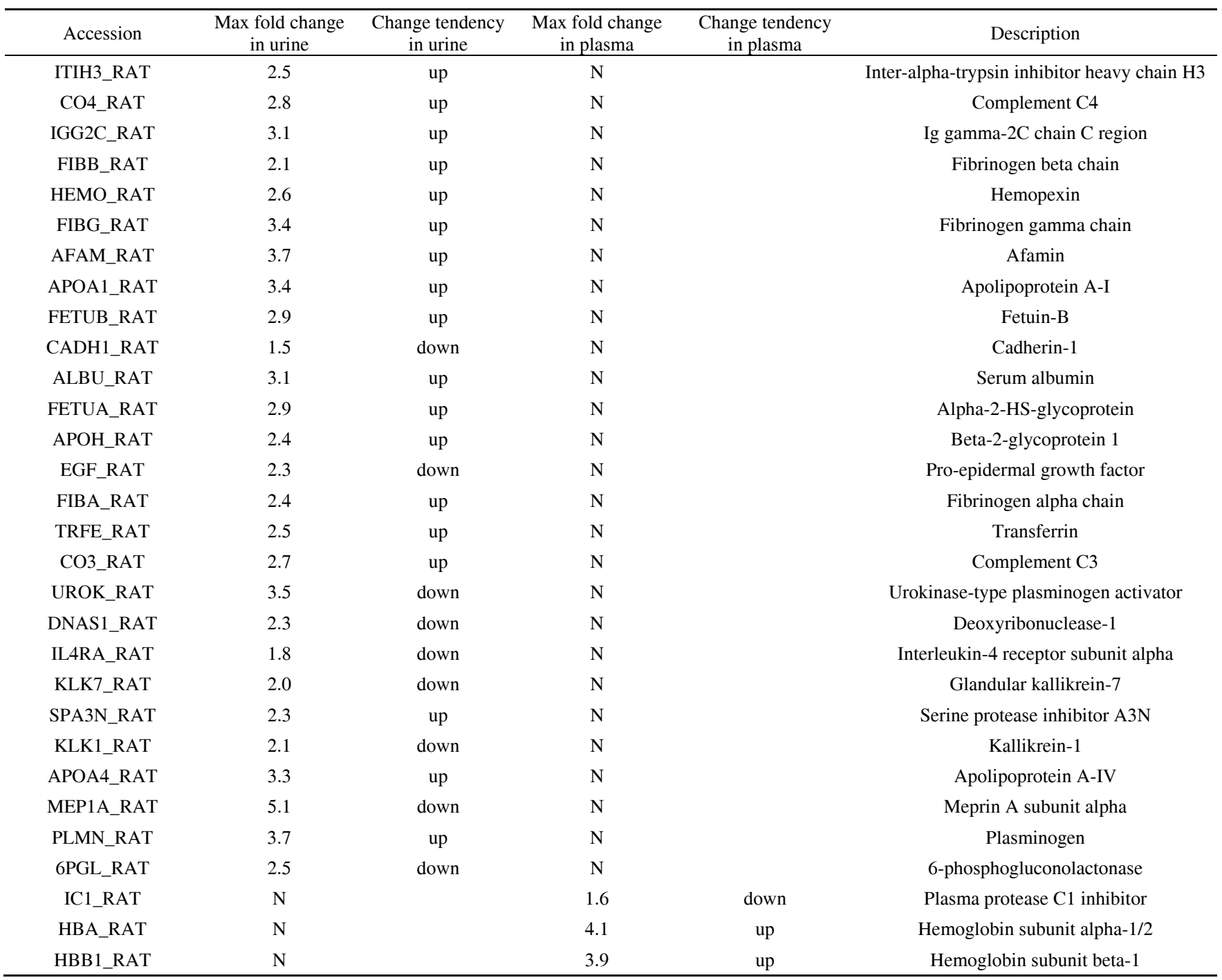

a) $\mathrm{N}$ indicates that the protein was not detected in the sample or failed to fulfil the quantitation criteria. 

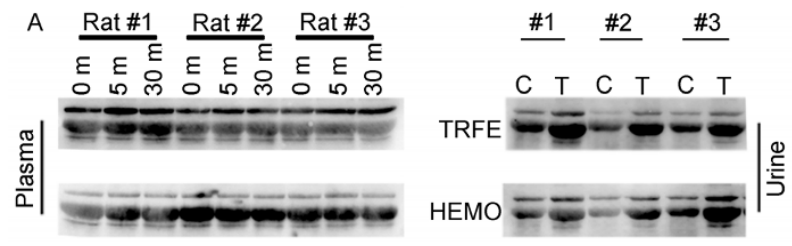

B Rat \#4 Rat \#5 Rat \#6

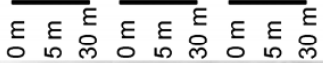

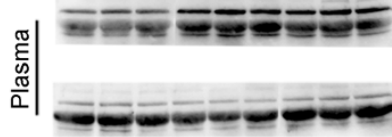

\#4 \#5 \#6

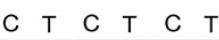

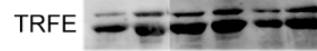

HEMO

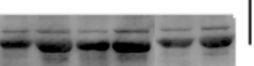

Figure 2 Western blot analysis of transferrin and hemopexin in urine and plasma. $20 \mu \mathrm{g} /$ lane of urine or plasma proteins were loaded into gels and analysed using Western blot. Changes in the levels of transferrin and hemopexin were comparable with those detected by LC-MS/MS analysis. A, Heparin treated group. B, Argatroban treated group. C, Before anticoagulants treated; $\mathrm{T}$, after anticoagulants treated.

(http://www.ingenuity.com/; Ingenuity Systems, USA). This analysis focused on the pathways and disease mechanisms in which the proteins are expected to be involved.

As shown in Figure 3, the differential proteins of anticoagulants treated rats take part in acute phase response signaling, LXR/RXR activation, coagulation system, intrinsic prothrombin activation pathway and extrinsic prothrombin activation pathway. The proteins involved in coagul- ation pathway included F2, FGA, FGG, FGB, KLKB1, PLAU, PLG and SERPINA 1.

\section{Discussion}

Biological fluids such as blood, urine and CSF serve as common sources of biomarkers, of which plasma is most routinely used [13]. Although plasma perfuses all tissues of the body and theoretically it can collect all the information of disease biomarkers, the role of homeostatic mechanisms in eliminating changes in these biomarkers should not be ignored. Changes in blood biomarker levels are unlikely to persist long enough for detection because they are disturbances of homeostasis. Because homeostasis helps to eliminate or excrete changes in biomarker levels into urine, exhaled air, bile and perspiration, these places may serve potential sources for biomarker discovery.

There are exceptions, however, for example, it is better to detect biomarkers in plasma when they are continuously secreted into blood or have a long half-life. Moreover, biomarkers for acute illnesses such as acute-necrotizing pancreatitis and acute myocardial infarction are excreted into blood in large amounts in a short period of time. Plasma analysis may be more helpful to monitor progression of diseases.

In this work, we demonstrated that more proteins could

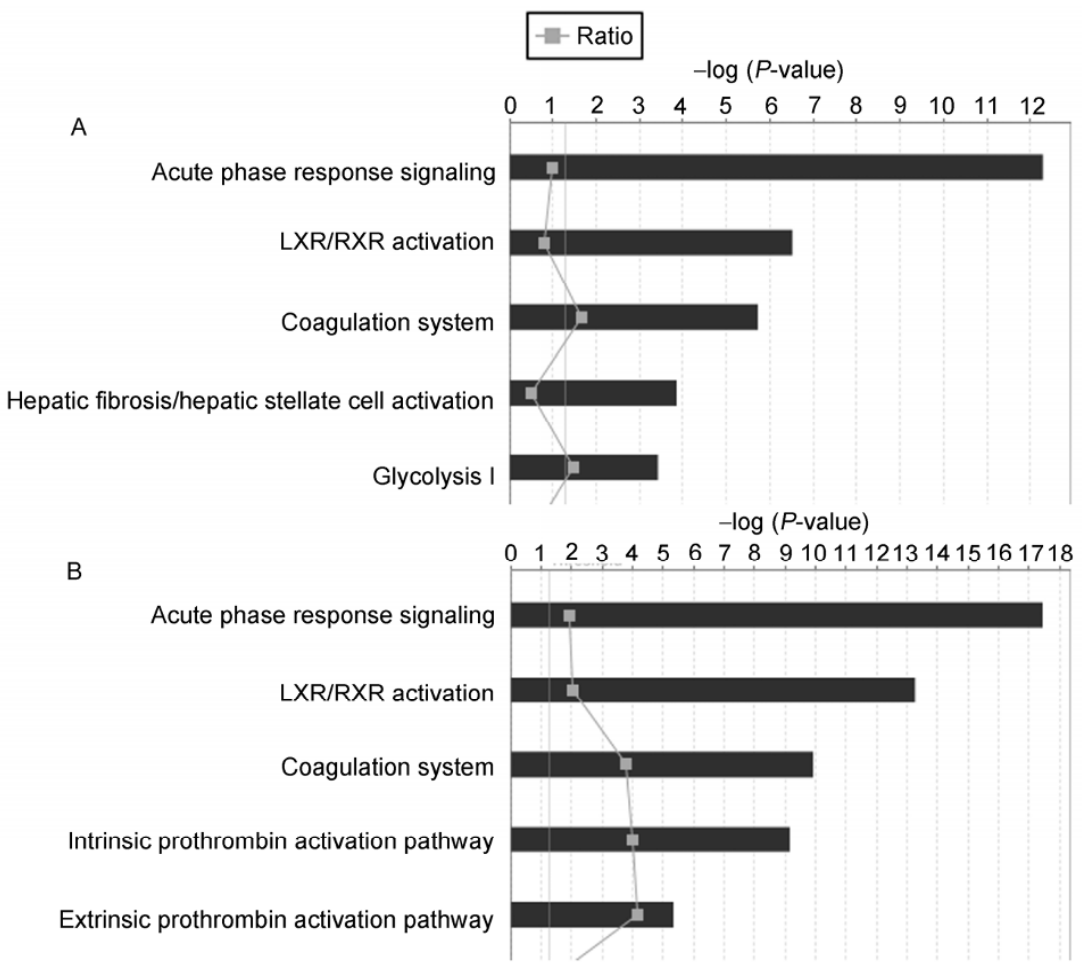

Figure 3 Functional analysis of the differential proteins via IPA. A, The Ingenuity Canonical Pathways in which the differential proteins of argatroban treated rats participated were phase response signaling, LXR/RXR activation, coagulation system and hepatic fibrosis/hepatic stellate cell activation. B, The Ingenuity Canonical Pathways in which the differential proteins of heparin treated rats participated were phase response signaling, LXR/RXR activation, coagulation system and intrinsic prothrombin activation pathway. 
be identified in urine than in plasma. There are several possible reasons. Firstly, any change that is introduced into the blood either internally or externally tends to be cleared by the liver, kidney and/or other organs via a variety of mechanisms to maintain the homeostasis of the blood. In contrast, urine is the place that most of the wastes in blood are dumped into, and thus tolerates changes to a much higher degree. Biomarkers are the measurable changes associated with a physiological or pathophysiological process. Therefore, they are more likely to be magnified and detectable in urine than their counterparts in blood.

Secondly, for proteomics and protein biomarker experiments, high dynamic ranges of protein concentrations in human plasma lead to a tremendous analytical challenge. Plasma proteins have a high dynamic range, spanning at least $10^{9}$ [14]. Albumin constitutes about half of the plasma proteins. In contrast, many potential biomarkers in plasma are at very low abundance. High-abundance proteins limit the identification of low-abundance proteins by LC-MS/ MS.

Thirdly, urine, as a filtrate of plasma, is relatively simple in composition, and the dynamic range of urinary proteins is about $10^{6}$ [15]. Accumulated changes in urine composition are not likely to be masked, and some molecular species which are difficult to detect in blood may be detected in urine. Therefore, more proteins would be identified in urine with the same experimental sensitivity.

Although methods such as multidimensional separation [16] can detect minor proteins or depletion of predominant proteins in plasma, they have several drawbacks. For example, these approaches can introduce additional variability; moreover, because some peptides and proteins bind to certain high abundance proteins $[17,18]$, the depletion strategy may lead to significant loss of information.

While technological limitations prevented the detection of many components of urine in the past, more than 2300 urinary proteins have recently been identified using high accuracy mass spectrometry [19], and technologies such as $\mathrm{CE}$ and SELDI-TOF MS have stimulated research into urinary biomarkers. In addition, urinary proteins containing post-translation modifications such as glycosylation [20-23] and phosphorylation [24,25] are potentially rich sources of disease biomarkers [26]. Moreover, profiling of urine peptides and metabolites also reveals potential for the identification of biomarkers for systemic diseases [27-29]. Despite this evidence, the importance of urine serving as a biomarker source remains underestimated. For example, we retrieved 316849 articles in a July 2013 search of PubMed using the keywords (('blood' OR serum OR 'plasma') and 'biomarker'), compared with 33930 articles found using (('urine' OR 'urinary') and 'biomarker'). In reality, the number of articles related to protein biomarkers in urine is no more than 450 in a manually organised database [30] (until June 2013, http://122.70.220.102/biomarker).

There have already been some data, which indicates that certain urine biomarkers are of higher quality than those from plasma. For example, urine angiostatin levels have been shown to strongly correlate with the renal pathology chronicity index [31], and urinary levels of ADAM 12 and MMP-9 have been used as non-invasive biomarkers in identifying women at increased risk of developing breast cancer [32]. Moreover, elevation in urinary desmosine levels has been shown to be associated with COPD [33].

Because urine accumulates a significant number of changes, urine samples show a greater degree of variability, particularly in protein concentration and volume [34], even though levels of constitutive proteins remain stable [15,35]. Such variability can be readily normalized using levels of creatinine [36], cystatin C [37] and N-acetyl- $\beta$-Dglucosaminidase (NAG) [38]. A significant challenge for biomarker discovery in urine remains, which is discerning which changes in urine composition were caused by which systematic factor. Questions such as this can be addressed by large-scale population studies to survey normal variations in urine composition, which will lay the foundation for biomarker discovery in urine.

Blood coagulation status is a critical physiological parameter, alterations of which can lead to embolism or haemorrhage. Because the use of blood samples to monitor coagulation status is harmful and invasive, particularly in patients with high risk of spontaneous bleeding, urine samples offer an alternative approach for monitoring the coagulation state, which can greatly benefit these patients.

In conclusion, using an identical proteomic analysis approach to profile the protein composition of rat urine and plasma samples before and after treatment with anticoagulants, we found that changes in the abundance of many proteins were consistently detected in urine samples but not in plasma. Urine may be the better source for biomarker discovery, because it accumulates changes, and can be collected noninvasively in large volumes. Faster and better biomarker discovery may lead to more accurate diagnosis and better health care.

We thank Sun Wei (Core Instrument Facility, Institute of Basic Medical Sciences, Chinese Academy of Medical Sciences/School of Basic Medicine, Peking Union Medical College) for technical assistance. This work was supported by the National Basic Research Program of China (2012CB517606, 2013CB530805), Expertise-Introduction Project for Disciplinary Innovation of Universities (B08007), National Natural Science Foundation of China (31200614), and Beijing Natural Science Foundation (5132028).

1 Yi J, Kim C, Gelfand CA. Inhibition of intrinsic proteolytic activities moderates preanalytical variability and instability of human plasma. J Proteome Res, 2007, 6: 1768-1781

2 Decramer S, Gonzalez de Peredo A, Breuil B, Mischak H, Monsarrat B, Bascands JL, Schanstra JP. Urine in clinical proteomics. Mol Cell Proteomics, 2008, 7: 1850-1862

3 Omenn GS, States DJ, Adamski M, Blackwell TW, Menon R, Hermjakob H, Apweiler R, Haab BB, Simpson RJ, Eddes JS, Kapp EA, Moritz RL, Chan DW, Rai AJ, Admon A, Aebersold R, Eng J, Hancock WS, Hefta SA, Meyer H, Paik YK, Yoo JS, Ping P, Pounds J, Adkins J, Qian X, Wang R, Wasinger V, Wu CY, Zhao X, Zeng R, Archakov A, Tsugita A, Beer I, Pandey A, Pisano M, Andrews P, Tammen H, Speicher DW, Hanash SM. Overview of the hupo plasma proteome project: results from the pilot phase with 35 collaborating laboratories and multiple analytical groups, generating a core dataset 
of 3020 proteins and a publicly-available database. Proteomics, 2005, 5: 3226-3245

4 Theodorescu D, Wittke S, Ross MM, Walden M, Conaway M, Just I, Mischak H, Frierson HF. Discovery and validation of new protein biomarkers for urothelial cancer: a prospective analysis. Lancet Oncol, 2006, 7: 230-240

5 Schaub S, Wilkins J, Weiler T, Sangster K, Rush D, Nickerson P. Urine protein profiling with surface-enhanced laser-desorption/ ionization time-of-flight mass spectrometry. Kidney Int, 2004, 65: 323-332

6 Jia L, Liu X, Liu L, Li M, Gao Y. Urimem, a membrane that can store urinary proteins simply and economically, makes the large-scale storage of clinical samples possible. Peer J PrePrints, 2013, 1: e37v31

7 Gao Y. Urine-an untapped goldmine for biomarker discovery? Sci China Life Sci, 2013, 56: 1145-1146

8 Thongboonkerd V, McLeish KR, Arthur JM, Klein JB. Proteomic analysis of normal human urinary proteins isolated by acetone precipitation or ultracentrifugation. Kidney Int, 2002, 62: 1461-1469

9 Garcia-Manzano A, Gonzalez-Llaven J, Lemini C, Rubio-Poo C. Standardization of rat blood clotting tests with reagents used for humans. Proc West Pharmacol Soc, 2001, 44: 153-155

10 Wisniewski JR, Zougman A, Nagaraj N, Mann M. Universal sample preparation method for proteome analysis. Nat Methods, 2009, 6: 359-362

11 Keller A, Nesvizhskii AI, Kolker E, Aebersold R. Empirical statistical model to estimate the accuracy of peptide identifications made by MS/MS and database search. Anal Chem, 2002, 74: 5383-5392

12 Hauck SM, Dietter J, Kramer RL, Hofmaier F, Zipplies JK, Amann B, Feuchtinger A, Deeg CA, Ueffing M. Deciphering membraneassociated molecular processes in target tissue of autoimmune uveitis by label-free quantitative mass spectrometry. Mol Cell Proteomics, 2010, 9: 2292-2305

13 Brunzel N. Fundamentals of Urine \& Body Fluid Analysis. Philadelphia: Saunders, 2004. 480

14 Pieper R, Gatlin CL, Makusky AJ, Russo PS, Schatz CR, Miller SS, Su Q, McGrath AM, Estock MA, Parmar PP, Zhao M, Huang ST, Zhou J, Wang F, Esquer-Blasco R, Anderson NL, Taylor J, Steiner S. The human serum proteome: display of nearly 3700 chromatographically separated protein spots on two-dimensional electrophoresis gels and identification of 325 distinct proteins. Proteomics, 2003, 3: 1345-1364

15 Nagaraj N, Mann M. Quantitative analysis of the intra- and inter-individual variability of the normal urinary proteome. J Proteome Res, 2011, 10: 637-645

16 Adkins JN, Varnum SM, Auberry KJ, Moore RJ, Angell NH, Smith RD, Springer DL, Pounds JG. Toward a human blood serum proteome: analysis by multidimensional separation coupled with mass spectrometry. Mol Cell Proteomics, 2002, 1: 947-955

17 Mehta AI, Ross S, Lowenthal MS, Fusaro V, Fishman DA, Petricoin EF, 3rd, Liotta LA. Biomarker amplification by serum carrier protein binding. Dis Markers, 2003, 19: 1-10

18 Shen Y, Kim J, Strittmatter EF, Jacobs JM, Camp DG, 2nd, Fang R, Tolie N, Moore RJ, Smith RD. Characterization of the human blood plasma proteome. Proteomics, 2005, 5: 4034-4045

19 Kentsis A, Monigatti F, Dorff K, Campagne F, Bachur R, Steen H. Urine proteomics for profiling of human disease using high accuracy mass spectrometry. Proteomics Clin Appl, 2009, 3: 1052-1061

20 Wang L, Li F, Sun W, Wu S, Wang X, Zhang L, Zheng D, Wang J, Gao Y. Concanavalin A-captured glycoproteins in healthy human urine. Mol Cell Proteomics, 2006, 5: 560-562

21 Sleat DE, Zheng H, Lobel P. The human urine mannose 6-phosphate glycoproteome. Biochim Biophys Acta, 2007, 1774: 368-372

22 Yang N, Feng S, Shedden K, Xie X, Liu Y, Rosser CJ, Lubman DM, Goodison S. Urinary glycoprotein biomarker discovery for bladder cancer detection using LC/MS-MS and label-free quantification. Clin Cancer Res, 2011, 17: 3349-3359
23 Halim A, Nilsson J, Rüetschi U, Hesse C, Larson G. Human urinary glycoproteomics; attachment site specific analysis of $\mathrm{N}$ - and $\mathrm{O}$-linked glycosylations by CID and ECD. Mol Cell Proteomics, 2012, 11: M111.013649

24 Khadjavi A, Barbero G, Destefanis P, Mandili G, Giribaldi G, Mannu F, Pantaleo A, Ceruti C, Bosio A, Rolle L, Turrini F, Fontana D. Evidence of abnormal tyrosine phosphorylated proteins in the urine of patients with bladder cancer: the road toward a new diagnostic tool? J Urol, 2011, 185: 1922-1929

25 Liu L, Liu X, Sun W, Li M, Gao Y. Unrestrictive identification of post-translational modifications in the urine proteome without enrichment. Proteome science, 2013, 11: 1

26 McDonald WH, Yates JR 3rd. Shotgun proteomics and biomarker discovery. Dis Markers, 2002, 18: 99-105

27 Chen T, Xie G, Wang X, Fan J, Qiu Y, Zheng X, Qi X, Cao Y, Su M, Wang X, Xu LX, Yen Y, Liu P, Jia W. Serum and urine metabolite profiling reveals potential biomarkers of human hepatocellular carcinoma. Mol Cell Proteomics, 2011, 10: M110 004945

28 Siwy J, Mullen W, Golovko I, Franke J, Zurbig P. Human urinary peptide database for multiple disease biomarker discovery. Proteomics Clin Appl, 2011, 5: 367-374

29 Nicholson JK, Wilson ID. Understanding 'global' systems biology: metabonomics and the continuum of metabolism. Nat Rev Drug Discov, 2003, 2: 668-676

30 Shao C, Li M, Li X, Wei L, Zhu L, Yang F, Jia L, Mu Y, Wang J, Guo Z, Zhang D, Yin J, Wang Z, Sun W, Zhang Z, Gao Y. A tool for biomarker discovery in the urinary proteome: a manually curated human and animal urine protein biomarker database. Mol Cell Proteomics, 2011, 10: M111 010975

31 Wu T, Du Y, Han J, Singh S, Xie C, Guo Y, Zhou XJ, Ahn C, Saxena $\mathrm{R}$, Mohan C. Urinary angiostatin-a novel putative marker of renal pathology chronicity in lupus nephritis. Mol Cell Proteomics, 2013, 12: 1170-1179

32 Pories SE, Zurakowski D, Roy R, Lamb CC, Raza S, Exarhopoulos A, Scheib RG, Schumer S, Lenahan C, Borges V, Louis GW, Anand A, Isakovich N, Hirshfield-Bartek J, Wewer U, Lotz MM, Moses MA. Urinary metalloproteinases: noninvasive biomarkers for breast cancer risk assessment. Cancer Epidemiol Biomarkers Prev, 2008, 17: 1034-1042

33 Huang JT, Chaudhuri R, Albarbarawi O, Barton A, Grierson C, Rauchhaus P, Weir CJ, Messow M, Stevens N, McSharry C, Feuerstein G, Mukhopadhyay S, Brady J, Palmer CN, Miller D, Thomson NC. Clinical validity of plasma and urinary desmosine as biomarkers for chronic obstructive pulmonary disease. Thorax, 2012, 67: 502-508

34 Thomas CE, Sexton W, Benson K, Sutphen R, Koomen J. Urine collection and processing for protein biomarker discovery and quantification. Cancer Epidemiol Biomarkers Prev, 2010, 19: 953-959

35 Weissinger EM, Wittke S, Kaiser T, Haller H, Bartel S, Krebs R, Golovko I, Rupprecht HD, Haubitz M, Hecker H, Mischak H, Fliser D. Proteomic patterns established with capillary electrophoresis and mass spectrometry for diagnostic purposes. Kidney Int, 2004, 65: 2426-2434

36 Jantos-Siwy J, Schiffer E, Brand K, Schumann G, Rossing K, Delles C, Mischak H, Metzger J. Quantitative urinary proteome analysis for biomarker evaluation in chronic kidney disease. J Proteome Res, 2009, 8: 268-281

37 Lankisch P, Wessalowski R, Maisonneuve P, Haghgu M, Hermsen D, Kramm CM. Serum cystatin C is a suitable marker for routine monitoring of renal function in pediatric cancer patients, especially of very young age. Pediatr Blood Cancer, 2006, 46: 767-772

38 Lemm G, Kuppers J, Frey R, Wingender W, Kuhlmann J. Monitoring of proteinuria in phase I studies in healthy male subjects. Eur J Clin Pharmacol, 1998, 54: 287-294

Open Access This article is distributed under the terms of the Creative Commons Attribution License which permits any use, distribution, and reproduction in any medium, provided the original author(s) and source are credited. 


\section{Supporting Information}

Figure S1 Comparison of urinary proteins before and after drugs administration on SDS PAGE. Lanes 1, 3, 5, 7, 9, 11, proteins before drugs treated; lanes $2,4,6$, proteins after heparin treated; lanes $8,10,12$, proteins after argatrabon treated. A total of $20 \mu \mathrm{g}$ of protein was equally loaded in each lane $(n=6$ animals).

Table S1 Changed proteins in argatroban treated group

Table S2 Numbers of proteins identified in each animal

The supporting information is available online at life.scichina.com and link.springer.com. The supporting materials are published as submitted, without typesetting or editing. The responsibility for scientific accuracy and content remains entirely with the authors. 